\title{
Effects of Phenyltriethoxysilane Concentration in Starting Solutions on Thermal Properties of Polyphenylsilsesquioxane Particles Prepared by a Two-Step Acid-Base Catalyzed Sol-Gel Process
}

\author{
Kenji TAKAHASHI ${ }^{\dagger}{ }^{K i y o h a r u ~ T A D A N A G A, ~ A t s u n o r i ~ M A T S U D A, ~}{ }^{*}$ \\ Akitoshi HAYASHI and Masahiro TATSUMISAGO \\ Department of Applied Chemistry, Graduate School of Engineering, Osaka Prefecture University, \\ 1-1, Gakuen-cho, Naka-ku, Sakai-shi, Osaka 599-8531 \\ *Department of Materials Science, Toyohashi University of Technology, 1-1, Hibarigaoka, Tempaku-cho, Toyohashi-shi, Aichi \\ $441-8580$
}

\begin{abstract}
Spherical polyphenylsilsesquioxane particles were prepared by a two-step acid-base catalyzed sol-gel process, in which various amounts of ethanol were used as a solvent to vary the concentration of phenyltriethoxysilane

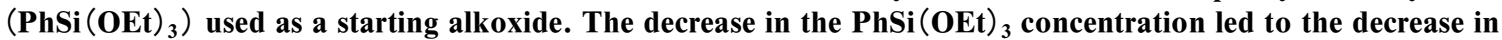
the average molecular weight and glass transition temperature of the polyphenylsilsesquioxanes. Thus, the change of the $\mathrm{PhSi}(\mathrm{OEt})_{3}$ concentration in the preparation of polyphenylsilsesquioxane particles by the two-step acid-base catalyzed sol-gel process is an effective means to control the glass transition temperature of the particles.

[Received August 25, 2006; December 18, 2006]
\end{abstract}

Key-words : Sol-gel method, Organic-inorganic hybrid material, Polyphenylsilsesquioxane, Particle, Glass transition

1. Introduction

Recently, much attention has been concentrated on various kinds of organic-inorganic hybrid materials. ${ }^{1,2)}$ In such materials, polyorganosilsesquioxanes, which have a siloxane structure with organic functional groups, are an attractive material because of their unique optical, mechanical, and thermal properties. ${ }^{3)-5)}$ Among the polyorganosilsesquioxanes, polyphenylsilsesquioxanes $\left(\mathrm{PhSiO}_{3 / 2}\right)$ have been studied for several decades by many researchers since Brown et al. ${ }^{6}$ referred to $\mathrm{PhSiO}_{3 / 2}$ which was prepared in their work as a ladder polymer with a stereoregular double chain structure. Many works have examined the preparation of $\mathrm{PhSiO}_{3 / 2}$ particles. ${ }^{7)-14)}$ Matsuda et al. prepared spiropyran-doped $\mathrm{PhSiO}_{3 / 2}$ particles by a two-step acid-base catalyzed sol-gel process and examined their photochromic characteristics. ${ }^{7)}$ Shibata et al. prepared rhodamine 6G-doped $\mathrm{PhSiO}_{3 / 2}$ particles using the two-step acid-base catalyzed sol-gel process and demonstrated their lasing behavior. ${ }^{8)}$ Hah et al. demonstrated a simple preparation process of hollow particles using the $\mathrm{PhSiO}_{3 / 2}$ particles prepared by the two-step acid-base catalyzed process. ${ }^{9)}$ We reported preparation of $\mathrm{PhSiO}_{3 / 2}$ particles using the two-step acid-base catalyzed sol-gel process and found that the $\mathrm{PhSiO}_{3 / 2}$ particles showed glass transition behavior. ${ }^{14)}$ This means that the $\mathrm{PhSiO}_{3 / 2}$ particles were thermally softened when they were heated at temperatures above the glass transition temperature $\left(T_{\mathrm{g}}\right)$. Moreover, it was also found that the $\mathrm{PhSiO}_{3 / 2}$ particles were thermally hardened after the first heating above $T_{\mathrm{g}}{ }^{14)}$ Masai et al. reported that thermal softening behavior of $\mathrm{PhSiO}_{3 / 2}$ prepared using a gelmelting process finally disappeared by a heat treatment because of the formation of a three-dimensional network. ${ }^{15)}$

Using the $\mathrm{PhSiO}_{3 / 2}$ particles prepared by the two-step acidbase catalyzed sol-gel process, we prepared $\mathrm{PhSiO}_{3 / 2}$ thick films with high transparency by the electrophoretic sol-gel deposition process. ${ }^{16)} \mathrm{We}$ also reported fabrication of convexshaped $\mathrm{PhSiO}_{3 / 2}$ micropatterns with high transparency by the electrophoretic deposition process using a hydrophobic-

\footnotetext{
${ }^{\dagger}$ Corresponding author: E-mail: kenji@chem.osakafu-u.ac.jp
}

hydrophilic-patterned surface. ${ }^{17)}$ In those reports, the thick films obtained were opaque just after the elecctrophoretic deposition process because of light-scattering among the particles at the interface and open spaces in the films. However, as a result of heat treatment, the particles in the films were changed morphologically from aggregates of spherical particles to a continuous phase. Eventually, thick films were obtained with high transparency. In these processes, the control of thermal properties, especially $T_{\mathrm{g}}$, of the particles is very important for us to prepare thick films with high transparency via low temperature sintering of the particles. In addition, the control of $T_{\mathrm{g}}$ is also important for us to fabricate convexshaped micropatterns with a curved surface such as quasispherical shapes, using surface tension of the supercooled liquid of the $\mathrm{PhSiO}_{3 / 2}$.

On the other hand, the use of solvents such as alcohols in the sol-gel process enables us to control the concentration of a starting alkoxide, leading to the suppression of the hydrolysis and condensation reactions. ${ }^{18)}$ Very recently, we found that thermoplastic and thermosetting properties of the $\mathrm{PhSiO}_{3 / 2}$ particles prepared by the two-step acid-base catalyzed sol-gel process were controlled by the concentration of phenyltriethoxysilane $\left(\mathrm{PhSi}(\mathrm{OEt})_{3}\right)$ used as a starting alkoxide. ${ }^{19)}$ In that study, we examined the effects of ethanol (EtOH) in the preparation of precursor solution on the properties of $\mathrm{PhSiO}_{3 / 2}$ particles. As a result, the $\mathrm{PhSiO}_{3 / 2}$ particles prepared in a solvent of $\mathrm{EtOH}$ were softened even on the repeated heating process, whereas the $\mathrm{PhSiO}_{3 / 2}$ particles prepared without $\mathrm{EtOH}$ became hard after the first heating process. Therefore, it is expected that the thermal properties, especially $T_{\mathrm{g}}$, of the $\mathrm{PhSiO}_{3 / 2}$ particles can be controlled by the concentration of $\mathrm{PhSi}(\mathrm{OEt})_{3}$ in the solvent of EtOH. Furthermore, we reported that the onset temperature for sintering of $\mathrm{PhSiO}_{3 / 2}$ particles prepared by the two-step acid-base catalyzed sol-gel process without using a solvent was mainly dominated by the molecular weight of the particles. ${ }^{20)}$

In the present study, we prepared $\mathrm{PhSiO}_{3 / 2}$ particles by the two-step acid-base catalyzed sol-gel process, in which various amounts of $\mathrm{EtOH}$ were used as a solvent to vary the concentration of $\mathrm{PhSi}(\mathrm{OEt})_{3}$ used as a starting alkoxide. The effect 
of the $\mathrm{PhSi}(\mathrm{OEt})_{3}$ concentration on the $T_{\mathrm{g}}$ and structures of $\mathrm{PhSiO}_{3 / 2}$ particles was investigated by differential scanning calorimetry (DSC), ${ }^{29} \mathrm{Si}$ cross-polarization magic-angle spinning-nuclear magnetic resonance (CP/MAS NMR), and gel permeation chromatography (GPC) measurements. The influence of the $\mathrm{PhSi}(\mathrm{OEt})_{3}$ concentration on characteristics of the $\mathrm{PhSiO}_{3 / 2}$ particles is discussed.

\section{Experimental}

\subsection{Preparation of $\mathrm{PhSiO}_{3 / 2}$ particles}

$\mathrm{PhSi}(\mathrm{OEt})_{3}$ dissolved in $\mathrm{EtOH}$ was firstly hydrolyzed with 0.01 mass \% hydrochloric acid at room temperature for $7 \mathrm{~h}$. Then, the resultant $\mathrm{PhSi}(\mathrm{OEt})_{3}$ sol was added to 4 mass\% ammonia water all at once. Microparticles were formed after the addition of the sol to the ammonia water, and the sol became opaque. The sol was additionally stirred for $20 \mathrm{~h}$ at room temperature at the stirring rate of around $1300 \mathrm{rpm}$. The molar ratio of $\mathrm{PhSi}(\mathrm{OEt})_{3}: \mathrm{EtOH}: \mathrm{H}_{2} \mathrm{O}$ (in hydrochloric acid) $: \mathrm{H}_{2} \mathrm{O}$ (in ammonia water) was fixed at $1: x: 20: 180$ $(x=0-100)$. In the preparation without using EtOH $(x=0)$, $\mathrm{PhSi}(\mathrm{OEt})_{3}$ was hydrolyzed directly with 0.01 mass $\%$ hydrochloric acid at room temperature for $7 \mathrm{~h}$. The particles were collected from the sol by centrifugation and dried under vacuum.

\subsection{Characterization of $\mathrm{PhSiO}_{3 / 2}$ particles}

Scanning electron microscopy (SEM) (JSM-5300, JEOL) was used for observation of shape and size of the particles. Thermal behavior of $\mathrm{PhSiO}_{3 / 2}$ particles was examined from DSC curves of repeated heating and cooling runs under $20^{\circ} \mathrm{C} /$ min (Pyris1 DSC, Perkin Elmer). The local structures around the $\mathrm{Si}$ atom were investigated using a ${ }^{29} \mathrm{Si} \mathrm{CP} / \mathrm{MAS}$ NMR spectrometer (Unity Inova 300, Varian). Polydimethylsiloxane $(-34.1 \mathrm{ppm})$ was used as an external standard. The NMR spectra were measured at $59.59 \mathrm{MHz}$, with contact time of $2.5 \mathrm{~ms}, 10 \mathrm{~s}$ of delay between pulses, and a sample spinning rate of $5000-5500 \mathrm{~Hz}$. The GPC measurements were performed using a pump (LC-10AD, Shimadzu), a detector (RID-6A, Shimadzu), and a column oven (CTO-10A, Shimadzu). A combination of two Shodex silica-gel columns
(CF-310HQ and GF-7MHQ) was used, with tetrahydrofuran (THF) as an eluent, at $40^{\circ} \mathrm{C}$. In GPC measurements of the $\mathrm{PhSiO}_{3 / 2}$ particles, the particles were dissolved in THF and the solution was filtered through a membrane filter with $0.45 \mu \mathrm{m}$ pore size. The concentration of the particles in the GPC measurements was fixed at 0.2 mass \%. In the GPC measurements of the supernatant liquids obtained after centrifugation, the supernatant liquids were mixed with THF in the weight ratio of the supernatant liquid : $\mathrm{THF}=3: 1$, and then the solutions were filtered through a membrane filter with $0.45 \mu \mathrm{m}$ pore size.

\section{Results and discussion}

In the preparation without $\mathrm{EtOH}(x=0), \mathrm{PhSi}(\mathrm{OEt})_{3}$ and diluted hydrochloric acid were immiscible at first, but the mixture became miscible after stirring for $7 \mathrm{~h}$ under the present preparation procedure because of the formation of $\mathrm{EtOH}$ as a by-product through the hydrolysis reaction. In contrast, the EtOH solution of $\mathrm{PhSi}(\mathrm{OEt})_{3}$ and diluted hydrochloric acid were miscible in the preparation using $\mathrm{EtOH}$.

Figure 1 shows SEM photographs of $\mathrm{PhSiO}_{3 / 2}$ particles prepared with (a) $x=0$, (b) $x=20$, (c) $x=50$, (d) $x=75$, and (e) $x=100\left(x=[\mathrm{EtOH}] /\left[\mathrm{PhSi}(\mathrm{OEt})_{3}\right]\right)$. Spherical $\mathrm{PhSiO}_{3 / 2}$ particles are observed in all compositions. The size distributions of the particles prepared in a solvent of EtOH (Figs. 1 (b) $-(d))$ are narrower than those of the particles prepared without a solvent of EtOH (Fig. 1 (a)). The local increase in concentration of the sol, which was added to the ammonia water, was prevented by the addition of $\mathrm{EtOH}$ into the sol. The resulting particles showed the narrow size distribution. On the other hand, the average diameter of the particles increases with an increase in $x$ when $x$ is more than 20 . The factor that determines the particle size has not yet been clarified. However, the affinity of $\mathrm{PhSiO}_{3 / 2}$ species toward ammonia water may affect the size of resulting particles when the sol, which was prepared under acidic conditions, was added to the ammonia water. Shibata et al. prepared $\mathrm{PhSiO}_{3 / 2}$ particles by the two-step acid-base catalyzed sol-gel process, without using a solvent. Results of that study indicated that the parti- (a)
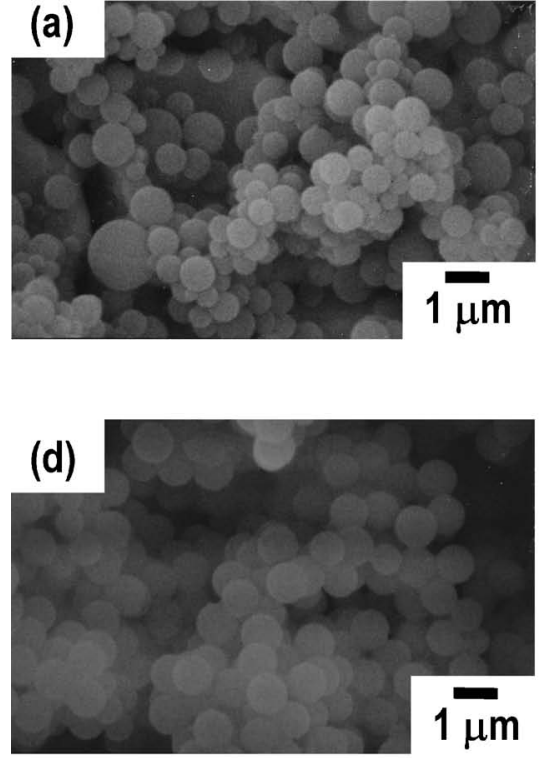
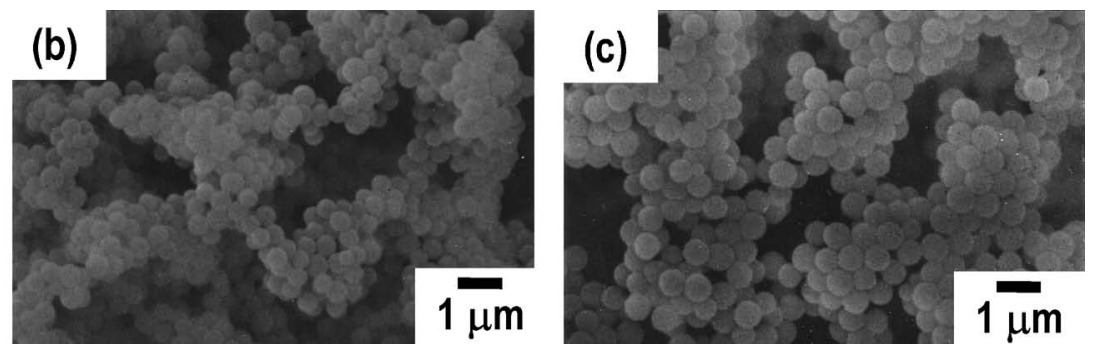

Fig. 1. SEM photographs of $\mathrm{PhSiO}_{3 / 2}$ particles prepared with (a) $x=0$, (b) $x=20$, (c) $x=50,(\mathrm{~d}) x=75$, and (e) $x=100$, where $x$ is the molar ratio $[\mathrm{EtOH}] /\left[\mathrm{PhSi}(\mathrm{OEt})_{3}\right]$.

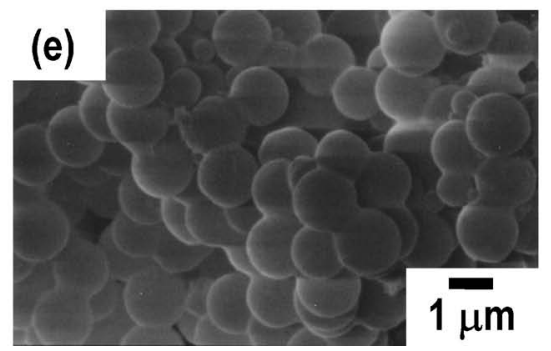




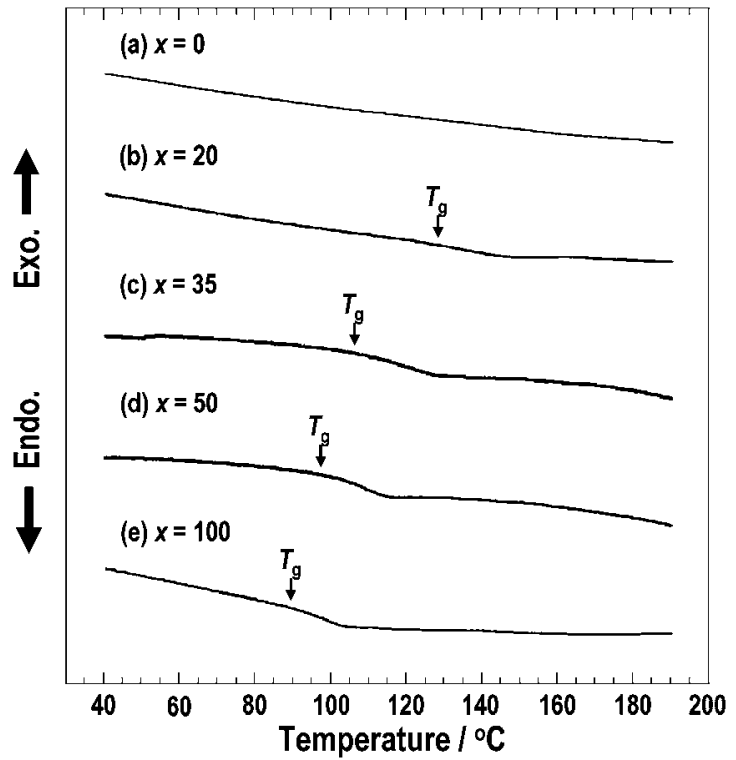

Fig. 2. DSC curves in the second heating run from 25 to $200^{\circ} \mathrm{C}$ at heating and cooling rate of $20^{\circ} \mathrm{C} / \mathrm{min}$ for $\mathrm{PhSiO}_{3 / 2}$ particles prepared with (a) $x=0$, (b) $x=20$, (c) $x=35$, (d) $x=50$, and (e) $x=100$.

cle size was altered according to the stirring speed.$^{8)}$ In the present study, we used a solvent and fixed the stirring speed at c.a. $1300 \mathrm{rpm}$, but the particle size was also varied by the concentration of $\mathrm{PhSi}(\mathrm{OEt})_{3}$ in a starting solution.

Figure 2 shows DSC curves in the second heating run from 25 to $200^{\circ} \mathrm{C}$ for the $\mathrm{PhSiO}_{3 / 2}$ particles prepared with (a) $x=0$, (b) $x=20$, (c) $x=35$, (d) $x=50$, and (e) $x=100$. In all as-prepared particles, it is presumed that the evaporation of residual solvents such as EtOH and water occurred on the first heating process. Consequently, the same heating was carried out again after the first heating process from 25 to $200^{\circ} \mathrm{C}$. It was confirmed that all particles showed thermal softening behavior below $160^{\circ} \mathrm{C}$. At $x=0$ (Fig. 2(a)), no appreciable change in DSC curves attributable to the glass transition is observed in the second heating run, meaning that the $\mathrm{PhSiO}_{3 / 2}$ prepared with $x=0$ was thermally hardened after the first heating up to $200^{\circ} \mathrm{C} .{ }^{19)}$ On the other hand, the endothermic change resulting from the glass transition in the composition range of $20 \leqq x \leqq 100$ was observed in the second heating run, indicating that the $\mathrm{PhSiO}_{3 / 2}$ was thermally softened after the first heating. ${ }^{19)}$ Furthermore, $T_{\mathrm{g}}$ is obviously decreased with a decrease in the $\mathrm{PhSi}(\mathrm{OEt})_{3}$ concentration (an increase in $x$ ( $\left.=[\mathrm{EtOH}] /\left[\mathrm{PhSi}(\mathrm{OEt})_{3}\right]\right)$ ), and $T_{\mathrm{g}}$ of the $\mathrm{PhSiO}_{3 / 2}$ particles is varied from around 90 to $130^{\circ} \mathrm{C}$ in the composition range of $20 \leqq x \leqq 100$.

Figure 3 shows ${ }^{29} \mathrm{Si} \mathrm{CP} / \mathrm{MAS}$ NMR spectra of the $\mathrm{PhSiO}_{3 / 2}$ particles prepared at the compositions of $x=0,20,50$, and 100 (a) before and (b) after a heat treatment at $200^{\circ} \mathrm{C}$ for $2 \mathrm{~h}$. For all particles, two peaks at $-69 \mathrm{ppm}$ due to $\mathrm{T}^{2}$ units with two bridging oxygens and at $-78 \mathrm{ppm}$ due to $\mathrm{T}^{3}$ units with three bridging oxygens ${ }^{10)}$ are observed before and after the heat treatment. In Fig. $3(\mathrm{a})$, the intensity of $\mathrm{T}^{2}$ units relative to that of $\mathrm{T}^{3}$ units of as-prepared $\mathrm{PhSiO}_{3 / 2}$ particles decreases as the $\mathrm{PhSi}(\mathrm{OEt})_{3}$ concentration decreases $(x(=[\mathrm{EtOH}] /$ $\left[\mathrm{PhSi}(\mathrm{OEt})_{3}\right]$ increases); the number of non-bridging oxygens decreases with decreasing $\mathrm{PhSi}(\mathrm{OEt})_{3}$ concentration. It was reported that the $\mathrm{PhSiO}_{3 / 2}$ species mainly composed of $\mathrm{T}^{2}$ units were well soluble in EtOH. ${ }^{9)}$ Thus, it is suggested that since the soluble $\mathrm{PhSiO}_{3 / 2}$ species mainly composed of

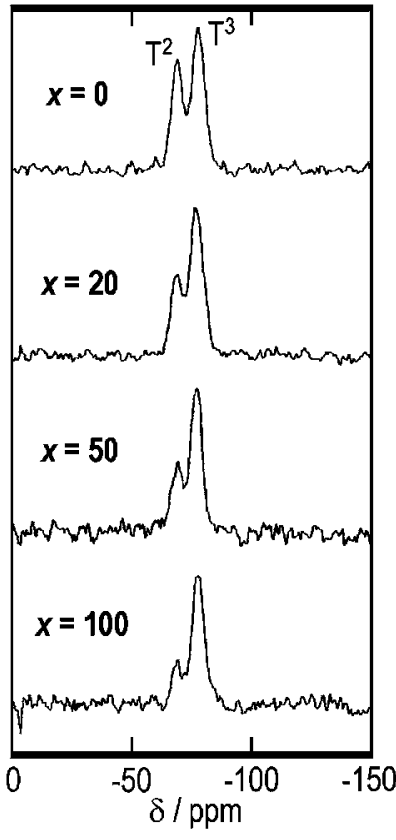

(a)

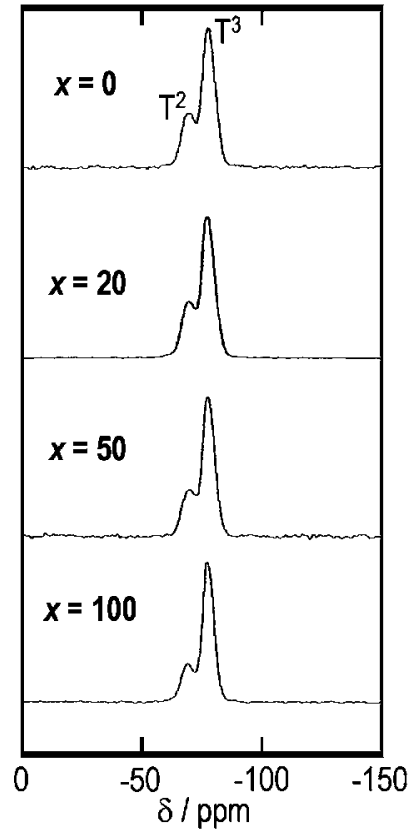

(b)
Fig. 3. ${ }^{29} \mathrm{Si} \mathrm{CP} / \mathrm{MAS}$ NMR spectra of $\mathrm{PhSiO}_{3 / 2}$ particles prepared at the compositions of $x=0,20,50$, and 100, (a) before and (b) after a heat treatment at $200^{\circ} \mathrm{C}$ for $2 \mathrm{~h}$.

$\mathrm{T}^{2}$ units are kept in EtOH-rich solution in the case of the large amount of EtOH, they remain in the supernatant liquid even after centrifugation.

As presented in Figs. 3 (a) and (b), the intensity of $\mathrm{T}^{2}$ units relative to that of $\mathrm{T}^{3}$ units of $\mathrm{PhSiO}_{3 / 2}$ particles heat-treated at $200^{\circ} \mathrm{C}$ is smaller than that of the as-prepared particles for all compositions, indicating that the siloxane networks of particles were developed through the heat treatment. In addition, the intensity of $\mathrm{T}^{2}$ units relative to that of $\mathrm{T}^{3}$ units of the particles with large amounts of $\mathrm{T}^{2}$ units $(x=0,20)$ is clearly decreased by the heat treatment at $200^{\circ} \mathrm{C}$. This result means that condensation reaction proceeded dramatically because the large amounts of non-bridging oxygens were present in $\mathrm{T}^{2}$ units. In contrast, the intensity of $\mathrm{T}^{2}$ units relative to that of $\mathrm{T}^{3}$ units of the particles with small mounts of $\mathrm{T}^{2}$ units $(x=50$, $100)$ is decreased slightly by the heat treatment at $200^{\circ} \mathrm{C}$, showing that condensation reaction proceeded only slightly because of the small amounts of non-bridging oxygens. Masai et al. proposed that the softening temperature of $\mathrm{PhSiO}_{3 / 2}$ prepared using a gel-melting process was mainly dominated by the number of bridging oxygens per $\mathrm{Si}$ atom. ${ }^{15)}$ However, in the present study, although the number of bridging oxygens per $\mathrm{Si}$ atom of the $\mathrm{PhSiO}_{3 / 2}$ particles prepared with $\mathrm{EtOH}$ was increased with a decrease in the $\mathrm{PhSi}(\mathrm{OEt})_{3}$ concentration, without regard to the heat treatment, $T_{\mathrm{g}}$ of the particles was decreased with decreasing the $\mathrm{PhSi}(\mathrm{OEt})_{3}$ concentration, as shown in Fig. 2. This result suggests that, for preparation of $\mathrm{PhSiO}_{3 / 2}$ particles using the two-step acid-base catalyzed sol-gel process, $T_{\mathrm{g}}$ of the particles is determined not by the number of bridging oxygens per Si atom; some other factor primarily affects $T_{\mathrm{g}}$ of the particles.

Figure 4 shows GPC curves of the $\mathrm{PhSiO}_{3 / 2}$ particles prepared with (a) $x=0$, (b) $x=20$, (c) $x=50$, and (d) $x=100$. No great difference exists in GPC curve between the samples at $x=0$ and 20 . However, the intensity of peaks at long reten- 


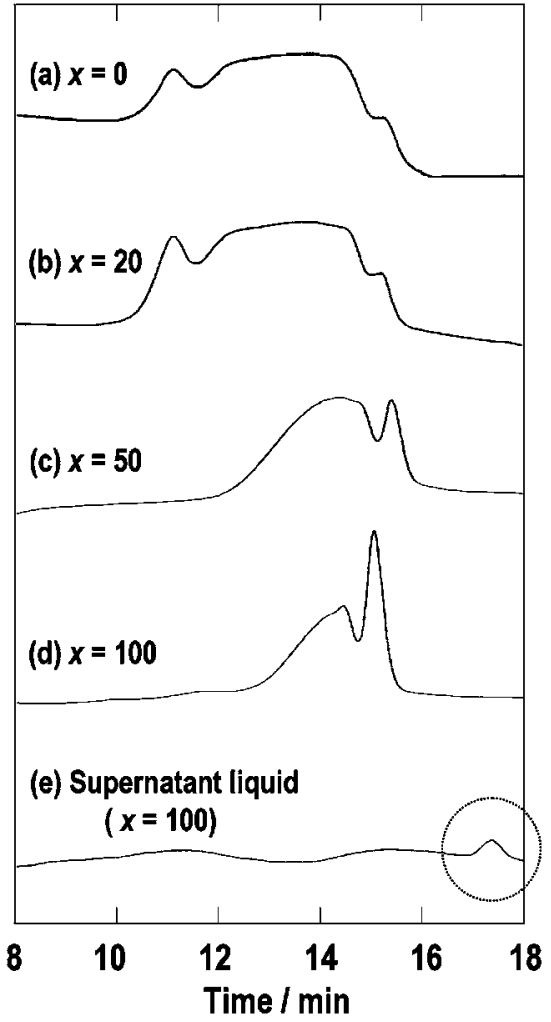

Fig. 4. GPC curves of $\mathrm{PhSiO}_{3 / 2}$ particles and supernatant liquid: (a) - (d), respectively, show curves of particles with $x=0,20,50$, and 100. (e) is for the curve of the supernatant liquid with $x=100$ obtained after centrifugation.

tion times in the composition range of $20 \leqq x \leqq 100$ is increased with a decrease in the $\mathrm{PhSi}(\mathrm{OEt})_{3}$ concentration (an increase in $\left.x\left(=[\mathrm{EtOH}] /\left[\mathrm{PhSi}(\mathrm{OEt})_{3}\right]\right)\right)$, meaning that the decrease in the average molecular weight of the $\mathrm{PhSiO}_{3 / 2}$ particles occurs concomitant with a decrease in the $\mathrm{PhSi}(\mathrm{OEt})_{3}$ concentration. Our previous work ${ }^{19)}$ demonstrated that the $\mathrm{PhSiO}_{3 / 2}$ particles prepared without EtOH $(x=0)$ were not dissolved completely in THF as an eluent $(0.2$ mass $\%$ solution $)$. The GPC curve of the particles with $x=0$ (Fig. 4(a)) shows only the result of $\mathrm{PhSiO}_{3 / 2}$ species with low molecular weight dissolved in THF and does not reflect the result of insoluble $\mathrm{PhSiO}_{3 / 2}$ species with high molecular weight. Consequently, the average molecular weight of the particles with $x=0$ may be larger than that of the particles prepared with $x=20$, but no great difference is apparent between them, as shown in Figs. 4 (a) and (b). These results support that the addition of EtOH suppresses the hydrolysis and condensation reactions. ${ }^{18)}$ The $T_{\mathrm{g}}$ of polymers such as polystylene usually increases with an increase in molecular weight. ${ }^{21)}$ Therefore, it can be concluded that the decrease in average molecular weight of the $\mathrm{PhSiO}_{3 / 2}$ particles engenders the decrease in $T_{\mathrm{g}}$. It is thus expected that the $T_{\mathrm{g}}$ of $\mathrm{PhSiO}_{3 / 2}$ particles can be controlled by the molecular weights of the $\mathrm{PhSiO}_{3 / 2}$ particles prepared by varying the concentration of $\mathrm{PhSi}(\mathrm{OEt})_{3}$ in $\mathrm{EtOH}$.

Figure 4(e) shows a GPC curve of the supernatant liquid with $x=100$ obtained after centrifugation. A small peak is visible at the retention time of about $17 \mathrm{~min}$, which was not observed in the $\mathrm{PhSiO}_{3 / 2}$ particles prepared with $x=100$ (Fig. 4(d)). The result suggests that the species with low molecular weight were included in the supernatant liquid. In turn, we can infer that the low molecular weight $\mathrm{PhSiO}_{3 / 2}$ spe- cies are soluble in EtOH-rich solution and remain in the supernatant liquid after centrifugation. In contrast, in the supernatant liquids with $x=20$ and 50, no appreciable peaks were apparent. From the discussion in Fig. 3 and Fig. 4, low molecular weight $\mathrm{PhSiO}_{3 / 2}$ species remaining in the supernatant liquid after centrifugation are presumed to be mainly composed of $\mathrm{T}^{2}$ units that are soluble in the EtOH-rich solution.

As described above, $T_{\mathrm{g}}$ of $\mathrm{PhSiO}_{3 / 2}$ particles prepared using the two-step acid-base catalyzed sol-gel process was controlled by changing the $\mathrm{PhSi}(\mathrm{OEt})_{3}$ concentration. The control of $T_{\mathrm{g}}$ for $\mathrm{PhSiO}_{3 / 2}$ particles is important for formation of transparent thick films using thermal sintering of the particles with heat treatment. Moreover, $T_{\mathrm{g}}$ control is also important to fabricate convex-shaped micropatterns with a curved surface such as quasi-spherical shapes using surface tension of the supercooled liquid of the $\mathrm{PhSiO}_{3 / 2}$.

\section{Conclusions}

Spherical $\mathrm{PhSiO}_{3 / 2}$ particles were prepared by the two-step acid-base catalyzed sol-gel process with different $\mathrm{PhSi}(\mathrm{OEt})_{3}$ concentrations. The decrease in the $\mathrm{PhSi}(\mathrm{OEt})_{3}$ concentration engendered a decrease in the molecular weight of the $\mathrm{PhSiO}_{3 / 2}$ particles and $T_{\mathrm{g}}$ of the particles. Thus, the change in the $\mathrm{PhSi}(\mathrm{OEt})_{3}$ concentration was an effective means to control $T_{\mathrm{g}}$ of the $\mathrm{PhSiO}_{3 / 2}$ particles. Furthermore, it was found that the $\mathrm{PhSiO}_{3 / 2}$ species with low molecular weight were soluble in EtOH-rich solution and remained in the supernatant liquid after centrifugation. Control of $T_{\mathrm{g}}$ is important for fabrication of micro-optical components using thermal softening behavior of the particles during heat treatment.

Acknowledgment This work was partially supported by a Grant-in-Aid from the Ministry of Education, Culture, Sports, Science and Technology of Japan. In addition, A. M. acknowledges New Energy and Industrial Technology Development Organization for support offered by the project "Development of Technology for Next-Generation Fuel Cells" of the programs for Strategic Development of PEFC Technologies for Practical Application.

\section{References}

1) Wight, A. P. and Davis, M. E., Chem. Rev., Vol. 102, pp. 3589-3614 (2002).

2) Sanchez, C., Lebeau, B., Chaput, F. and Boilot, J.-P., $A d v$. Mater., Vol. 15, pp. 1969-1994 (2003).

3) Voronkov, M. G. and Lavrentyev, V. I., Top. Curr. Chem., Vol. 102, pp. 199-236 (1982).

4) Baney, R. H., Itoh, M., Sakakibara, A. and Suzuki, T., Chem. Rev., Vol. 95, pp. 1409-1430 (1995).

5) Loy, D. A., Baugher, B. M., Baugher, C. R., Schneider, D. A. and Rahimian, K., Chem. Mater., Vol. 12, pp. 3624-3632 (2000).

6) Brown, J. F., Vogt, L. H., Katchman, A., Eustance, J. W., Kiser, K. M. and Krantz, K. W., J. Am. Chem. Soc., Vol. 82, pp. 6194-6195 (1960).

7) Matsuda, R., Yamaguchi, M. and Okamoto, H., KokaiTokkyo-Koho, Heisei 5-140313 [in Japanese].

8) Shibata, S., Yamane, M., Kamada, K., Ohta, K., Sasaki, K. and Masuhara, H., J. Sol-Gel Sci. Tech., Vol. 8, pp. 959-964 (1997).

9) Hah, H. J., Kim, J. S., Jeon, B. J., Koo, S. M. and Lee, Y. E., Chem. Commun., pp. 1712-1713 (2003).

10) Choi, J. Y., Kim, C. H. and Kim, D. K., J. Am. Ceram. Soc., Vol. 81, pp. 1184-1188 (1998).

11) Ma, C. and Kimura, Y., Polym. J., Vol. 34, pp. 709-713 (2002).

12) Arkhireeva, A. and Hay, J. N., J. Mater. Chem., Vol. 13, pp. 
3122-3127 (2003).

13) Arkhireeva, A., Hay, J. N. and Manzano, M., Chem. Mater., Vol. 17, pp. 875-880 (2005).

14) Matsuda, A., Sasaki, T., Hasegawa, K., Tatsumisago, M. and Minami, T., J. Ceram. Soc. Japan, Vol. 108, pp. 830-835 (2000).

15) Masai, H., Takahashi, M., Tokuda, Y. and Yoko, T., J. Mater. Res., Vol. 20, pp. 1234-1241 (2005).

16) Katagiri, K., Hasegawa, K., Matsuda, A., Tatsumisago, M. and Minami, T., J. Am. Ceram. Soc., Vol. 81, pp. 2501-2503 (1998).

17) Takahashi, K., Tadanaga, K., Matsuda, A. and Tatsumisago,
M., J. Mater. Res., Vol. 21, pp. 1255-1260 (2006).

18) Brinker, C. J. and Scherer, G. W., "Sol-Gel Science, The Physics and Chemistry of Sol-Gel Processing," Academic Press, Boston (1990) pp. 123-127.

19) Takahashi, K., Tadanaga, K., Matsuda, A., Hayashi, A. and Tatsumisago, M., J. Sol-Gel Sci. Tech., in press.

20) Sasaki, T., Matsuda, A., Minami, T. and Tatsumisago, M., J. Ceram. Soc. Japan, Vol. 110, pp. 1005-1009 (2002).

21) Painter, P. C. and Coleman, M. M., "Fundamentals of Polymer Science,” Technomic Publishing Co., Inc. Company, Lancaster (1997) pp. 290-303. 